\title{
Microstructure and Texture Distribution of Ti-6Al-4V Alloy Joints \\ Friction Stir Welded below $\beta$-transus Temperature
}

\author{
Sungook Yoon*, Rintaro Ueji, Hidetoshi Fujii \\ Joining and Welding Research Institute, Osaka University, \\ 11-1, Mihogaoka, Ibaraki, Osaka, 567-0047, Japan
}

Abstract: Ti-6Al-4V alloy plates with a thickness of $5 \mathrm{~mm}$ were successfully joined by friction stir welding (FSW) at a significantly lower than the $\beta$-transus temperature, and the microstructure and texture evolution in the stir zone (SZ) along the thickness and transverse directions of the joint were clarified. The fully equiaxed $\alpha$ structure was observed even near the top surface in the $50 \mathrm{rpm}$ joint, while a mixture of the lamellar structure with equiaxed $\alpha$ grains was found near the top surface in the $150 \mathrm{rpm}$ joint. The existence of the lamellar structure resulted in a strong [0001] $\alpha$ concentration in this area due to the variant selection during the phase transformation. A bimodal structure was formed in the retreating side (RS) of the SZ obtained at $50 \mathrm{rpm}$, and a higher area fraction of the coarse grain structure was found in the RS of the SZ center than in the RS located $0.1 \mathrm{~mm}$ from the top surface due to the gradients in the strain, strain rate and temperature. The local texture measured by EBSD clarified that $[0001] \alpha$ was perpendicular to the welding direction on the advancing side (AS), and gradually rotated toward to the welding direction when the measurement positions were moved to the RS in the SZ of the Ti alloy joints. The difference in the distribution of the $[0001] \alpha$ concentration direction in 
the SZ along the transverse direction between the FSWed $\mathrm{Mg}$ and $\mathrm{Ti}$ alloy joints should be due to the difference in the plastic behavior caused by higher work hardening ability of the Ti alloy.

\footnotetext{
*Corresponding author, E-mail: yoon@jwri.osaka-u.ac.jp, yoonsungook@ gmail.com, Tel./fax: +81 668798663 .
}

Keywords: friction stir welding, titanium, microstructure, texture, $\beta$-tansus.

\section{Introduction}

The FSW of the Ti alloys is being actively studied and some studies on the microstructure and the mechanical properties of the FSWed Ti-6Al-4V alloy have been reported. Zhang et al. (2008) conducted the FSW of Ti-6Al-4V plates at the temperatures above the $\beta$-transus. They reported that the microstructure of the joints showed the fully lamellar structure and the mechanical properties of the joints increased with the decreasing heat input. Su et al. (2013) also performed the FSW of Ti-6Al-4V plates above the $\beta$-transus temperature and pointed out that the mechanical properties of the joints increased with the decreasing heat input. On the other hand, Fujii et al. (2010) performed the FSW of commercial purity Ti below the $\beta$-transus temperature and pointed out that the preferable mechanical properties were obtained. In addition, Kitamura et al. (2013) reported that they successfully obtained the fine equiaxed $\alpha$ structure by conducting the FSW of the Ti-6Al-4V alloy below the $\beta$-transus temperature and clarified that preferable 
mechanical properties were obtained compared with the joints welded above the $\beta$-transus temperature.

The FSW is characterized by both frictional heat and material flow generated from the rotation of the tool. The crystallographic texture is one of the keys that provides the material flow during the FSW since the texture can be characterized by plastic deformation. Therefore, the texture should be investigated in order to control the microstructure and the mechanical properties of the FSW joints. However, a limited number of studies has been reported on the texture during the FSW of the Ti-6Al-4V alloy. Davies et al. (2011) investigated the FSW joint of the Ti-6Al-4V alloy produced with the peak temperature above the $\beta$-transus temperature and they reported that the $\alpha$ phase texture in the fully lamellar structure was inherited from the shear deformation texture of the high-temperature $\beta$ phase. Pilchak and Williams (2011) also examined the texture of the $\beta$ phase of the FSW joints of the Ti-6Al-4V alloy and clarified that a simple shear texture was identified. These reports are concerned with the plastic deformation of the $\beta$ phase, while those of the $\alpha$ phase have not been reported.

The Ti-6Al-4V is categorized as an $\alpha+\beta$ alloy, thus not only the recrystallization, but also the phase transformation should play an important role in the resultant microstructural features. The microstructural features are determined by the recrystallization in the $\alpha$ phase when the FSW is performed at a relatively lower temperature. In addition, hexagonal close-packed (hcp) metals frequently exhibit a plastic anisotropy, therefore, the study on the texture is also important to clarify the mechanical properties of the joints. In this study, the FSW of Ti-6Al-4V plates was performed at lower tool rotation rates and the distribution of the microstructural features in the SZ was investigated. 


\section{Experimental procedures}

Ti-6Al-4V plates with a thickness of $5 \mathrm{~mm}$ and a width of $50 \mathrm{~mm}$ were used as the base metal (BM). A Co-based alloy tool with a taper-shaped probe, which had a $25 \mathrm{~mm}$ shoulder diameter, a $3.4 \mathrm{~mm}$ probe tip diameter and a $4.9 \mathrm{~mm}$ probe length, was used for the FSW. The FSW was performed at the tool rotation rates of $50 \mathrm{rpm}$ or $150 \mathrm{rpm}$ under a constant tool traverse speed of $10 \mathrm{~mm} / \mathrm{min}$. The tool rotation axis was tilted by $1^{\circ}$ to the tool traverse direction and argon shielding gas was continuously supplied in order to prevent oxidation of the joints. The microstructure observations of the joints were carried out by optical microscopy (OM) and scanning electron microscopy (SEM) equipped with an electron back scattered diffraction (EBSD) system. An elemental analysis was conducted by energy dispersive spectroscopy (EDS). The joints were cut perpendicular to the welding direction and the cross section was ground. The specimen for the $\mathrm{OM}$ observation was etched in a $2 \mathrm{ml} \mathrm{HF}+6 \mathrm{ml} \mathrm{HNO}_{3}+92 \mathrm{ml}$ water solution. The specimen for the SEM and the EBSD observations was polished in a $5 \mathrm{ml} \mathrm{HClO}_{4}+35 \mathrm{ml}$ $\mathrm{C}_{4} \mathrm{H}_{9} \mathrm{OH}+60 \mathrm{ml} \mathrm{CH} \mathrm{CH}_{3} \mathrm{OH}$ solution at a voltage of $30 \mathrm{~V}$ at $-40^{\circ} \mathrm{C}$. The EBSD mappings were conducted on the cross section parallel to both the normal direction (ND) and the transverse direction (TD). Vickers hardness tests were performed on the cross-section parallel to the ND of the joints with a load of $200 \mathrm{~g}$ for a duration time of $15 \mathrm{~s}$.

\section{Results and discussion}

3.1 Microstructure of base metal 
Figure 1 (a) shows the orientation color map of the BM obtained by EBSD measurement. The microstructure of the BM consisted of elongated coarse $\alpha$ grains with a grain size of about $20 \mu \mathrm{m}$ and fine equiaxed $\alpha$ grains with a grain size of around $5 \mu \mathrm{m}$. The $\beta$ phase with a volume fraction of about $5 \%$ was located at the $\alpha$ grain boundaries. Figure 1 (b) shows the [0001] $\alpha$ pole figure measured at the BM. The maximum intensity (Imax) value is shown at the bottom of the pole figure. The texture showed a strong concentration of [0001] which is roughly parallel to the welding direction. Frederick and Lenning (1975) reported that the formation of the basal texture in the Ti alloys deformed by multidirectional hot rolling.

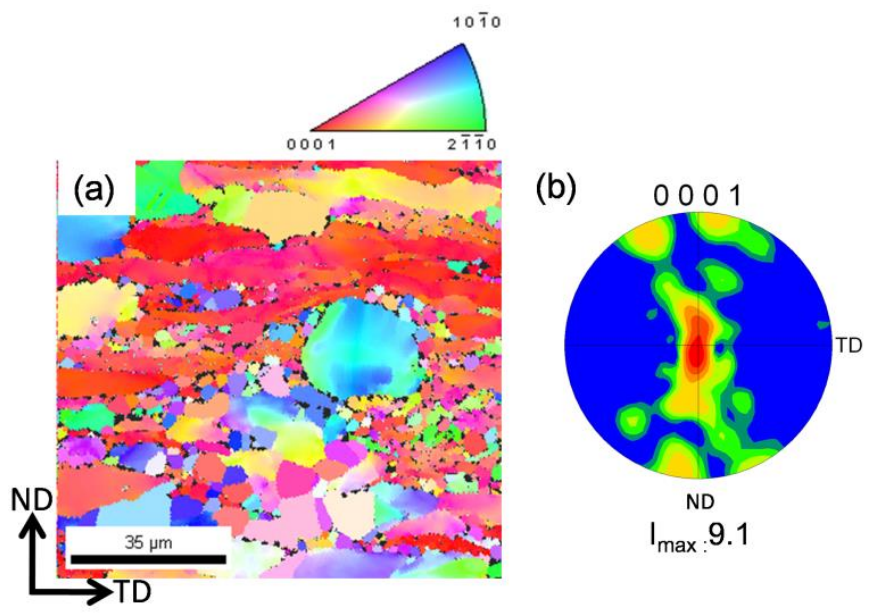

Fig. 1 Microstructure features of BM; (a) Orientation color map of and (b) [0001] pole figure.

3.2 Macrostructure of the joints

Figure 2 shows the optical macrographs of the cross section of the FSW joints obtained at 50 or $150 \mathrm{rpm}$. The horizontal and vertical directions of these figures are the TD and ND, respectively. The left side and the right side are the AS and RS, respectively. Basin-shape SZs were clearly 
visible in the center part of FSW joints and no visible welding defect such as a void was found. However, some contaminated areas were found in the $150 \mathrm{rpm}$ joint as indicated by the black rectangle in Fig. 2 (b). The contamination areas significantly decreased with the decreasing tool rotation rate. The detailed investigation of the contamination area was conducted by EDS and EBSD. The EDS measurement clarified that the contamination areas show the lack of Ti and the existence of $\mathrm{Co}$ and $\mathrm{W}$ which are the dominant components of the FSW tool. Thus, the contaminations are due to the tool wear during the FSW.

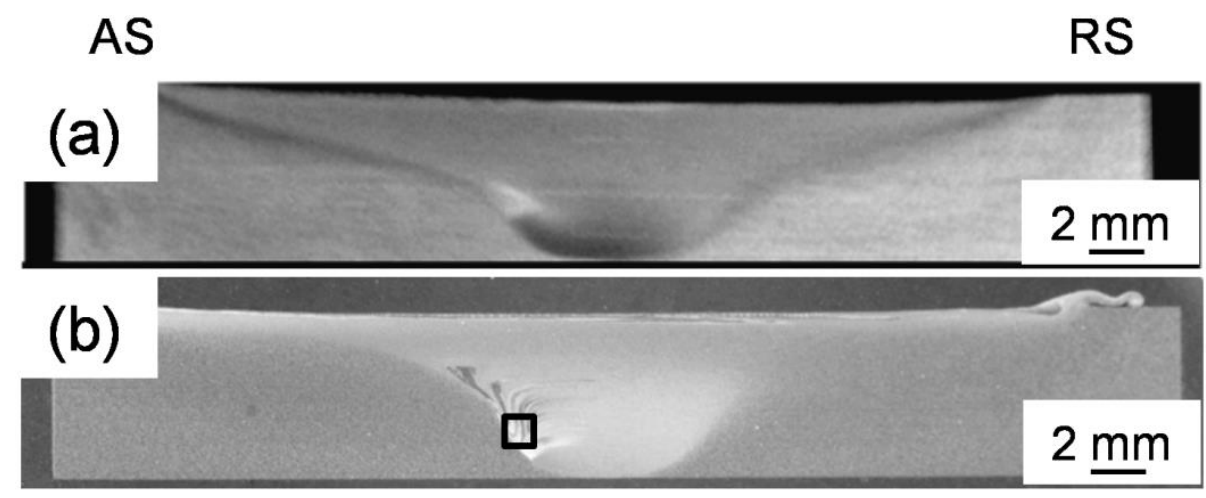

Fig. 2 Optical macrographs of cross-sections perpendicular to tool traverse direction of FSWed Ti-6Al-4V plates; (a) $50 \mathrm{rpm}, 10 \mathrm{~mm} / \mathrm{min}$ and (b) $150 \mathrm{rpm}, 10 \mathrm{~mm} / \mathrm{min}$.

Figure 3 shows the EBSD mapping measured in the area indicated by the black rectangle in Fig. 2 (b). These figures show (a) the $\alpha$ phase (hcp) orientation color map and (b) the $\beta$ phase (bcc) orientation color map. The SZ mainly consisted of the fine equiaxed $\alpha$ grains while the contamination area was mainly consisted of coarse equiaxed $\beta$ grains. This should be due to the effect of the Co, which is a strong $\beta$-stabilizer that dissolved in the Ti matrix. Therefore, the $\beta$ phase was stabilized at room temperature. 

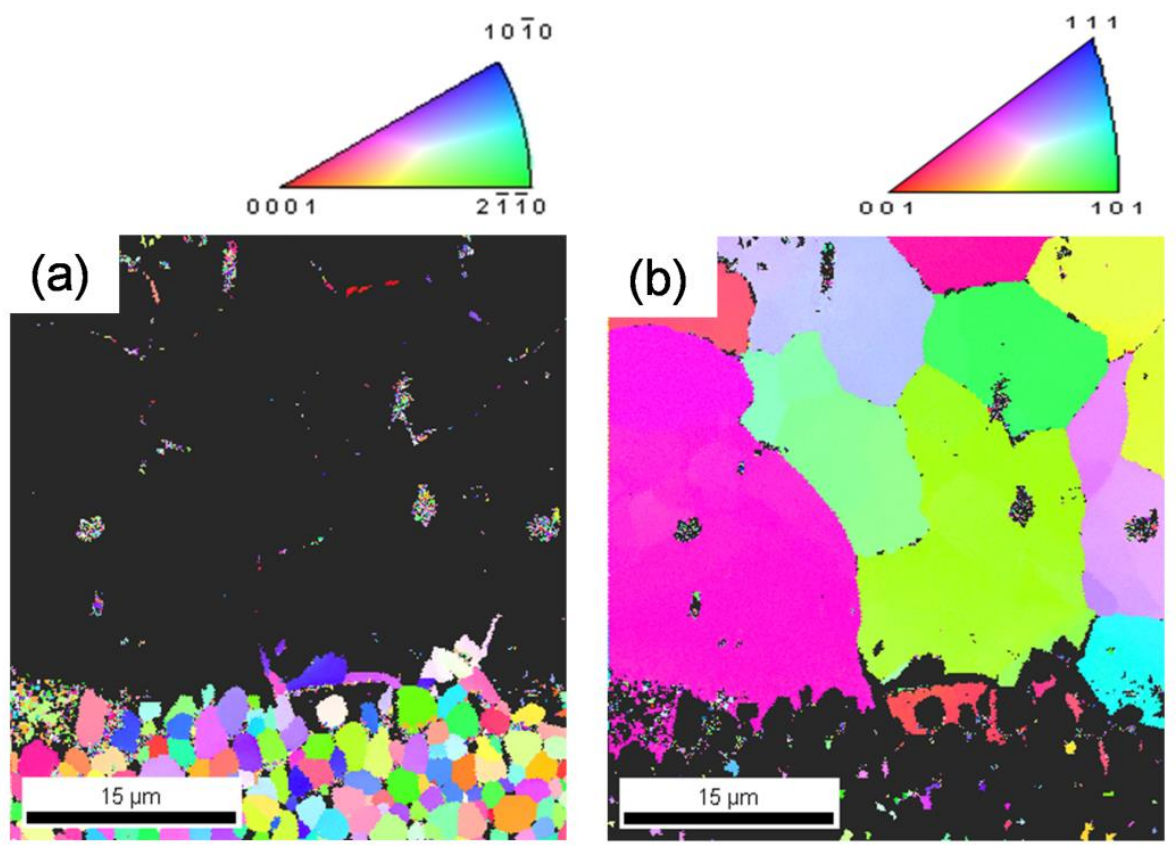

Fig. 3 Orientation color maps of (a) $\alpha$ phase and (b) $\beta$ phase of rectangle area in Fig. 2(b).

\subsection{Structure distribution in thickness}

In addition to the change in the metal flow in the thickness, the temperature gradient is one of the characteristic features of the FSW of Ti due to its low thermal conductivity, therefore, the microstructure in the thickness should be examined. Figure 4 shows the $\alpha$ phase orientation color maps of the SZ obtained at the tool rotation rate of $50 \mathrm{rpm}$. The EBSD measurements were conducted at the top, the center and the bottom part of the SZ as indicated in the macrograph above the orientation color maps. The color indicates the crystal orientations parallel to the welding direction with the color key shown in the triangle at the top right of this figure. The microstructure of the SZ exhibited the fully equiaxed structure and uniform morphology in all the measurement positions. The results of the microstructure observations clearly indicated that 
the peak temperature was significantly lower than the $\beta$-transus temperature for the entire thickness of the weld. In addition, the mean equiaxed $\alpha$ grain size decreased with the increasing distance from the top surface. This grain size distribution in thickness should be due to the temperature gradient. Yoon et al. (2015) has already clarified the grain size distribution in thickness of the Ti-6Al-4V alloy joints and the distribution should be due to the temperature gradient caused by the lower thermal conductivity. The mean equiaxed $\alpha$ grain size in the top, the center and the bottom part of the SZ was $1.5,1.2$ and $0.7 \mu \mathrm{m}$, respectively.

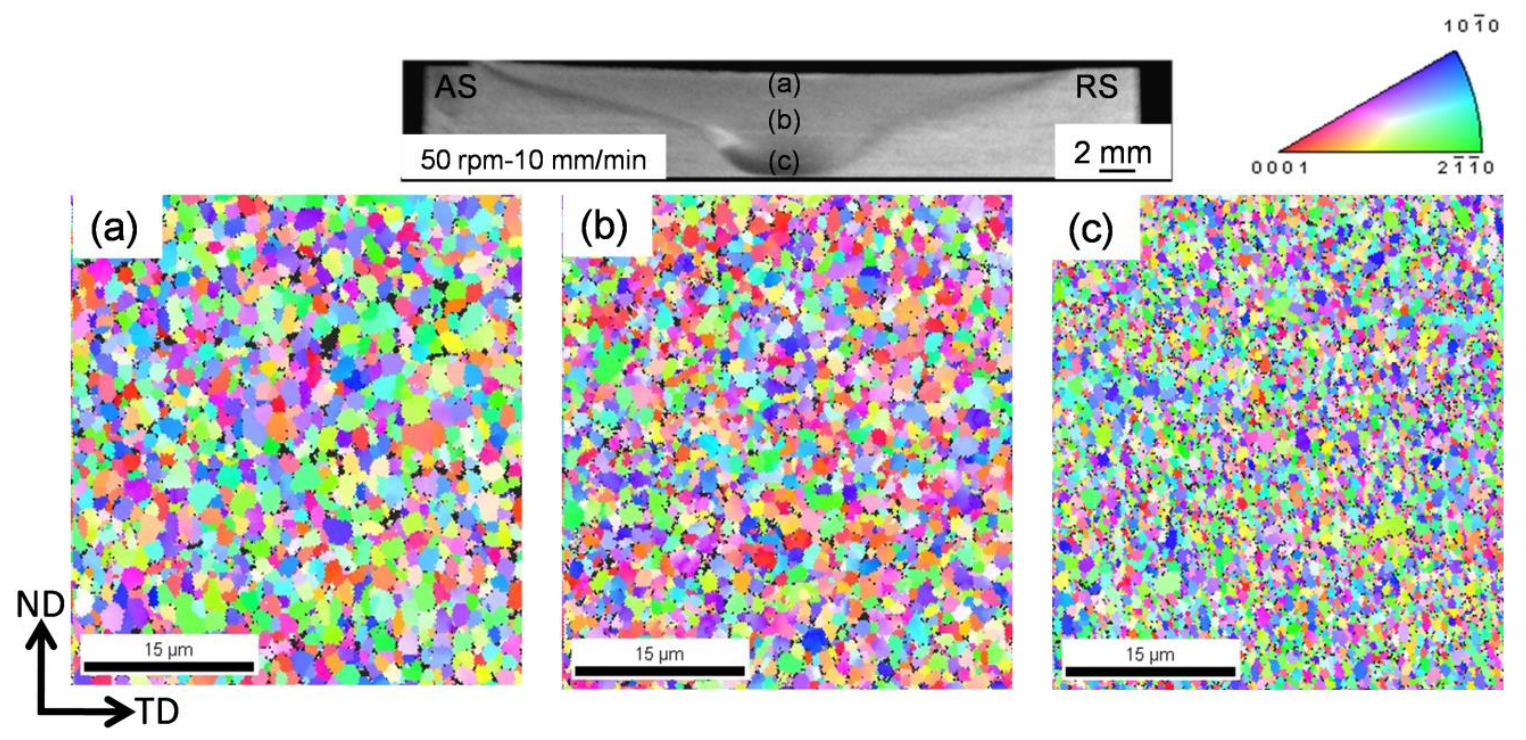

Fig. 4 Orientation color maps of SZ obtained at $50 \mathrm{rpm}, 10 \mathrm{~mm} / \mathrm{min}$; (a) top surface (b) SZ center and (c) bottom surface.

Figure 5 shows $\alpha$ phase orientation color maps of the SZ obtained at the tool rotation rate of $150 \mathrm{rpm}$. When compared to the $50 \mathrm{rpm}$ joint, different microstructure morphology was observed in the $150 \mathrm{rpm}$ joint. At all the measurement locations, the grain size in the $150 \mathrm{rpm}$ joint is larger. In addition, some of these grains, especially near the top surface, has an orientation 
gradient indicating the gradual change in the color of a grain. The grains with the orientation gradient in the EBSD data appear to correspond with the location where the $\alpha$ lamellar structure evolved as shown in Fig.6. It should be noted that the dominant component of the microstructure still maintains the $\alpha$ equiaxed grains even near the top surface. This means that the FSW at 150 rpm still maintains its peak temperature lower than the $\beta$-transus temprerature. The increase in the grain size is due to the lager heat input caused by the higher tool rotation rate, which is typically observed in the FSW joint of several metallic materials. The mean equiaxed $\alpha$ grain size in the center and the bottom part of the SZ was 1.8 and $0.9 \mu \mathrm{m}$, respectively.

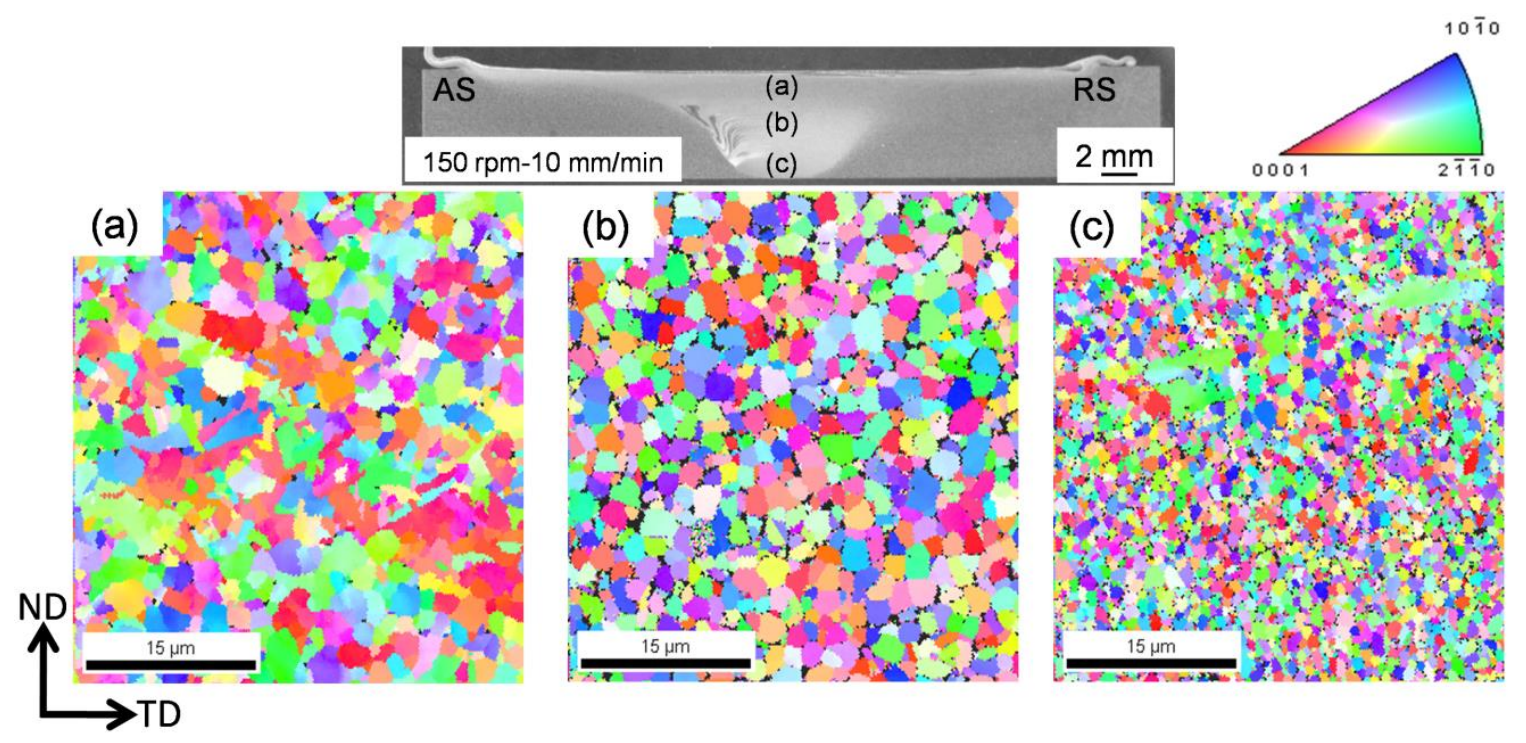

Fig. 5 Orientation color maps of SZ obtained at $150 \mathrm{rpm}, 10 \mathrm{~mm} / \mathrm{min}$; (a) top surface (b) SZ center and (c) bottom surface. 


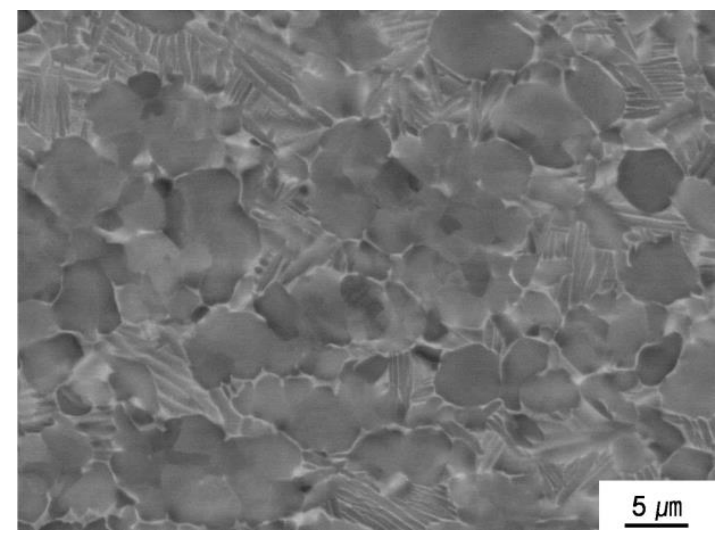

Fig. 6 Backscattered electron image of near top surface of SZ obtained at tool rotation rate of 150 rpm.

Figure 7 shows the hardness distribution of the cross-section along the ND of the SZs in the joints obtained at the tool rotation rates of $50 \mathrm{rpm}$ and $150 \mathrm{rpm}$. The hardness values of the 50 rpm joint were higher than that of the $150 \mathrm{rpm}$ joint in all the measurement positions due to the finer equiaxed $\alpha$ grain size as shown in Fig.4 and Fig.5. In addition, the hardness values increased with the increasing distance from the top surface. These hardness distributions are well agreed with the equiaxed $\alpha$ grain size distribution as already described.

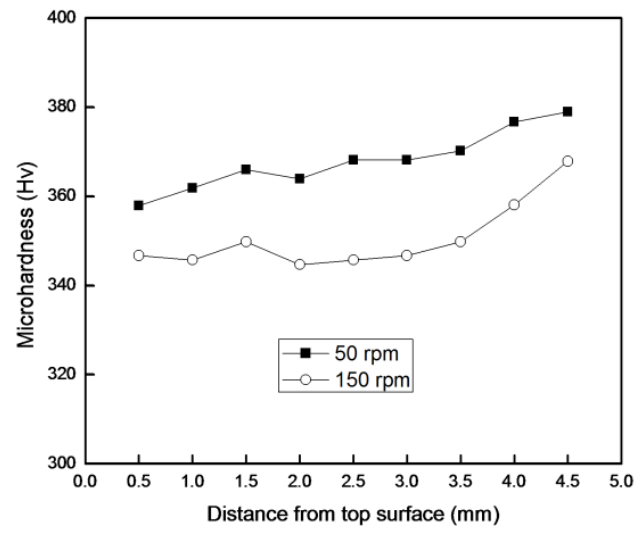

Fig. 7 Hardness distribution of SZ obtained at $50 \mathrm{rpm}, 10 \mathrm{~mm} / \mathrm{min}$ and $150 \mathrm{rpm}, 10 \mathrm{~mm} / \mathrm{min}$ in thickness. 
Figure 8 shows the [0001] $\alpha$ pole figures measured by EBSD in the SZs of the joints obtained at the tool rotation rates of (a) 50 and (b) $150 \mathrm{rpm}$. The measurements areas $(\mathrm{A}, \mathrm{B}$, and $\mathrm{C}$ ) are indicated on the macrographs of the cross section at the top of this figure. The horizontal and the vertical directions of the pole figures are parallel to the TD and the ND, respectively, and the center of the pole figures indicates the welding direction. The left and right sides indicate the AS and RS, respectively.
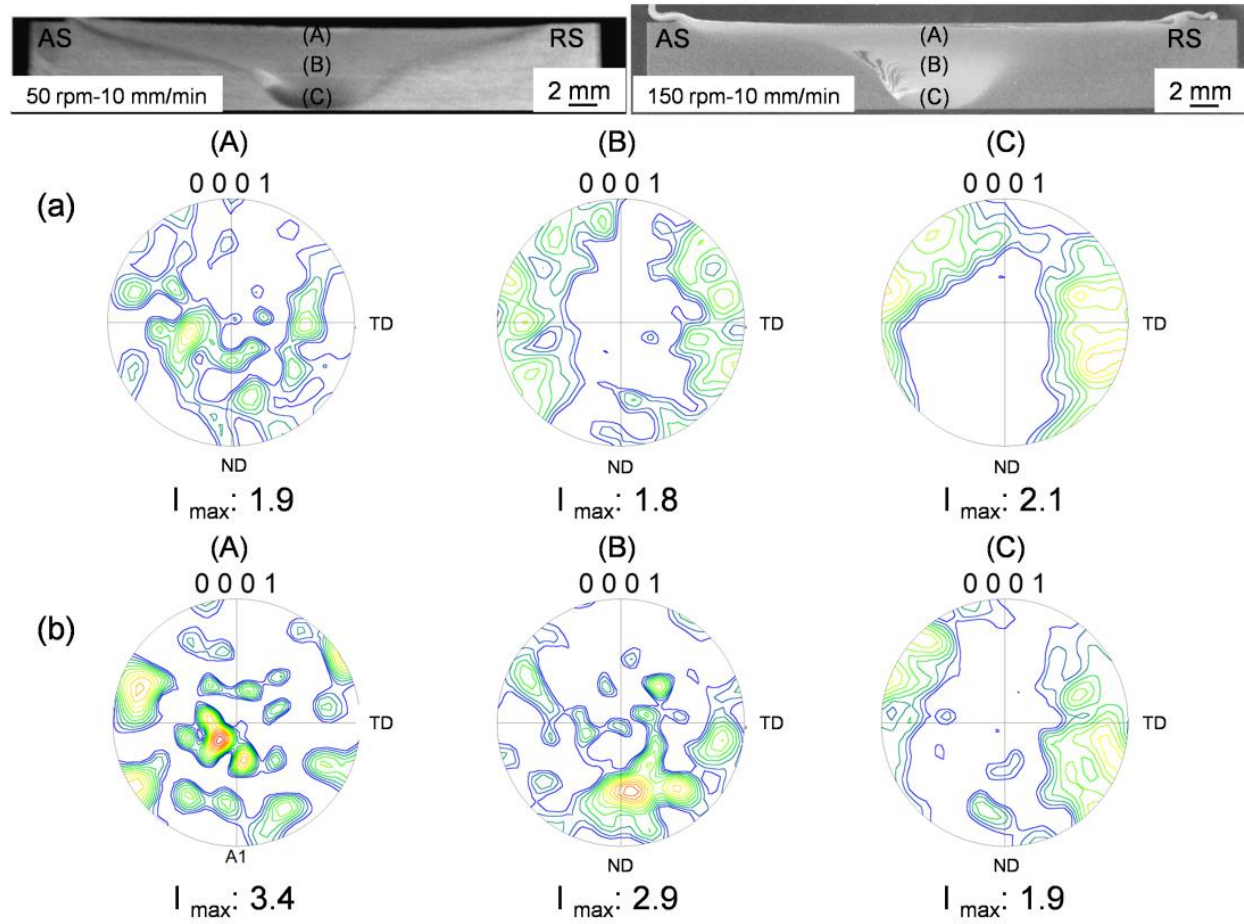

Fig. 8 [0001] pole figures obtained at tool rotation rates of (a) $50 \mathrm{rpm}$ and (b) $150 \mathrm{rpm}$. (measurement positions are illustrated on macrograph above pole figures)

The pole figures can be distinguished into two types in accordance with the orientation concentrations. These include one strong concentration of [0001], which is parallel to the welding direction, and a broadened concentration of [0001], which is roughly parallel to the TD. The former type can be found in the top surface (A) of the $50 \mathrm{rpm}$ joint, the top surface and the 
$\mathrm{SZ}$ center (A, B) in the $150 \mathrm{rpm}$ joint. The latter type can be found in the $\mathrm{B}$ and $\mathrm{C}$ in the $50 \mathrm{rpm}$ joint and $\mathrm{C}$ in the $150 \mathrm{rpm}$ joint. The lower heat input condition showed a lower maximum intensity (Imax) in the entire weld, however, the area includes a lamellar structure (A in the 150 rpm joint) which showed a higher texture intensity. Yoon et al. (2015) already pointed out that the areas include lamellar structure exhibited a higher texture intensity in the FSW joints of the Ti-6Al-4V alloy. The maximum texture intensity increases when the thermal cycle of the FSW includes the phase transformation to the lamellar structure probably due to the variant selection effect.

3.4 Structure distribution along the transverse direction

As noted in the macroscopic structure shown in Fig.2, the $150 \mathrm{rpm}$ joint has some contamination around the periphery of the SZ, so that the examination of the microstructure distribution along the transverse direction was conducted with a convergent focus on the $50 \mathrm{rpm}$ joint.

Figure 9 shows the orientation color maps obtained in the regions located at a depth of $1.0 \mathrm{~mm}$ and $2.5 \mathrm{~mm}$ from the top surface along the AS to RS. The measurements areas (A, B and C) are indicated on the schematic illustration of the cross section at the top of this figure. The microstructures of these locations mainly consisted of fine equiaxed $\alpha$ grains, and a limited number of coarse $\alpha$ grains can be found in the RS of the SZ. The mean grain size of the fine equiaxed $\alpha$ grain was about $1.3 \mu \mathrm{m}$ in the regions located at a depth of $1.0 \mathrm{~mm}$ from the top surface. This means that no significant difference in the grain size is found along the TD. At a 
depth of $2.5 \mathrm{~mm}$ from the top surface, coarse $\alpha$ grains can be more frequently found on the RS (region C) compared to that below $1.0 \mathrm{~mm}$ from the top surface. The mean grain size of the fine equiaxed $\alpha$ was about $1.2 \mu \mathrm{m}$ in the regions located at a depth of $2.5 \mathrm{~mm}$ from the top surface.

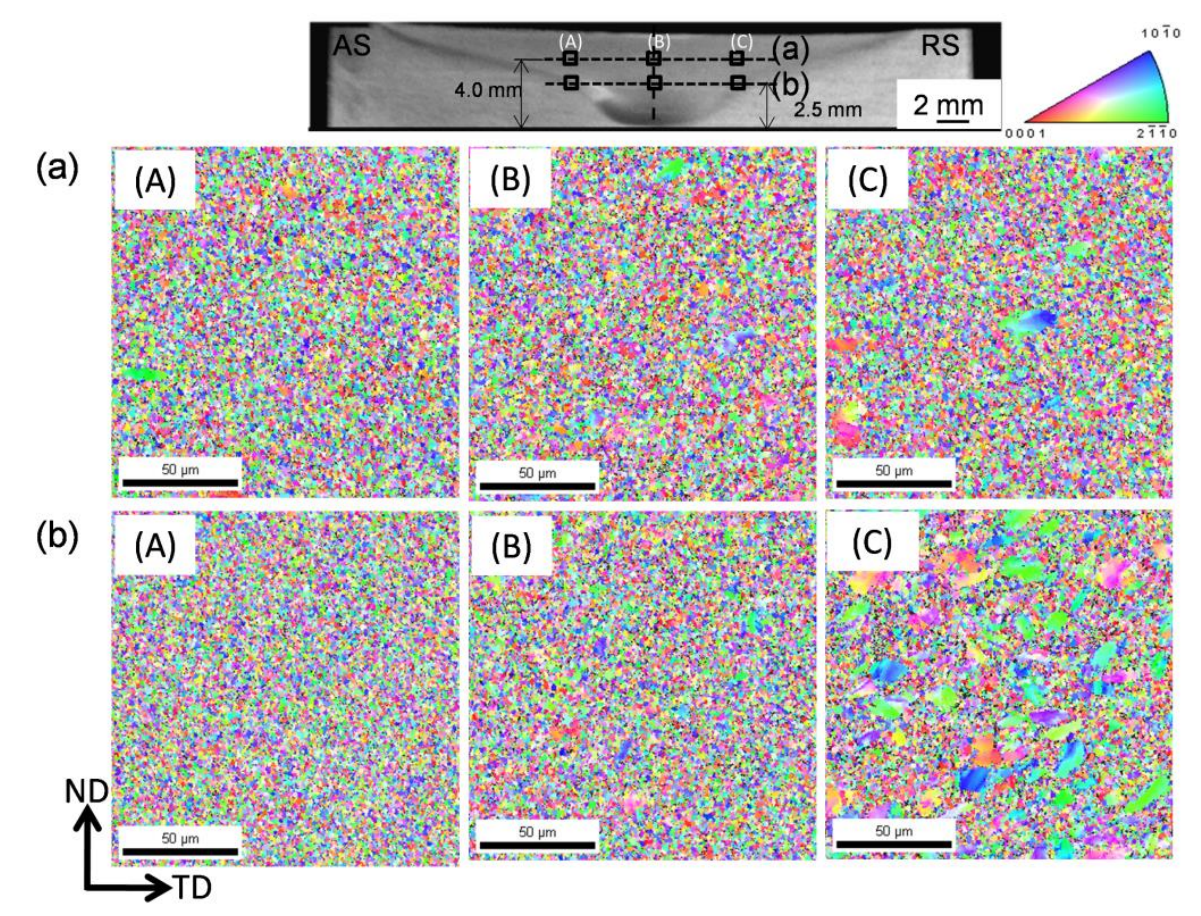

Fig. 9 orientation color maps of SZ obtained at $50 \mathrm{rpm}$ joint in regions located at (a) depth of 1.0 $\mathrm{mm}$ from surface and (b) $2.5 \mathrm{~mm}$ from top surface. (measurement positions are illustrated on macrograph above orientation color maps)

Figure 10 shows the grain boundary maps of the SZ obtained at the locations of Fig. 9 (a) (C) and Fig. 9 (b)(C). These are the regions where the coarse grains were found. Low angle boundaries (LABs) with misorientations of $0.5-15^{\circ}$ and high angle boundaries (HABs) with misorientations above $15^{\circ}$ are marked by the green and black lines, respectively. The HABs are considered as the dominant structure in all the maps. The LAB is difficult to be found in the fine grains. On the other hand, all of the coarse $\alpha$ grains include a large amount of the LAGBs 
indicating the remaining as-deformed state structures which are surrounded by the fine recrystallized structures. This bimodal structure may imply that the recrystallization did not completely occur in these regions. This heterogeneous microstructure in the SZ is probably due to the gradients in the strain, strain rate and temperature. Aval et al. (2011) investigated the microstructure of the FSWed AA5086 alloy joints and reported that the AS exhibited higher strain than that of the RS. The frequent appearance of coarse grain structures in the RS should be due to the lower strain than that of the AS. In addition, Reynolds (2008) clarified that the strain rate during the FSW should be related with the SZ width thus, the strain rate decreases with the increasing distance from the top surface since the width of the SZ decreases with the increasing distance from the top surface and this strain rate distribution should result in the existence of more coarse grain structures in the SZ center than in the regions located at a depth of $1.0 \mathrm{~mm}$ from the surface.
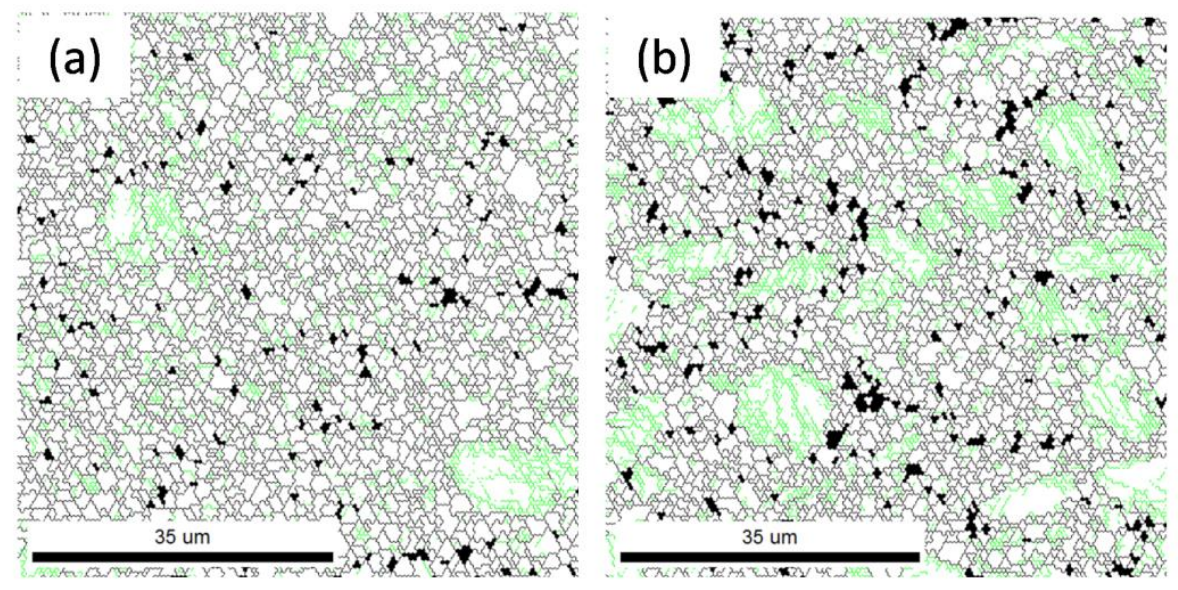

Fig. 10 Grain boundary maps obtained in the regions of (a) RS located at depth of $1.0 \mathrm{~mm}$ from top surface and (b) RS located at depth of $2.5 \mathrm{~mm}$ from top surface. (low angle boundaries and high angle boundaries are indicated by green and black lines, respectively) 
Figure 11 shows the [0001] $\alpha$ and the [11-20] $\alpha$ pole figures measured by EBSD in the regions located at a depth of $1.0 \mathrm{~mm}$ from the top surface in the $50 \mathrm{rpm}$ joint. The measurements areas (a, b, c, d, e) are indicated on the schematic illustration of the cross section at the top of Fig. 11. The directions of the maximum concentration are denoted by " $\mathrm{X}$ " on the [0001] pole figures.
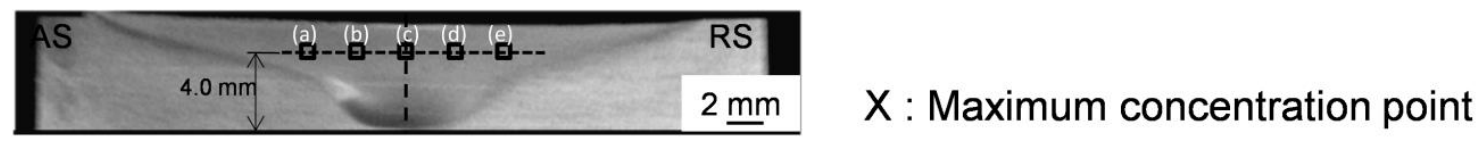

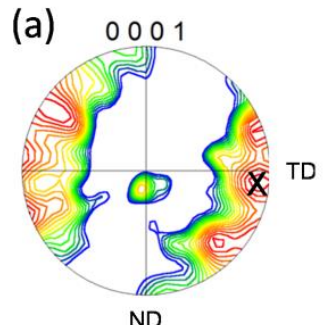

$I_{\max }: 1.4$

(a)

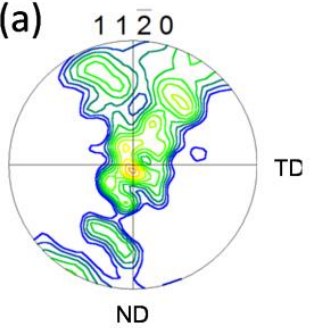

$I_{\max }: 1.2$ (b) 0001

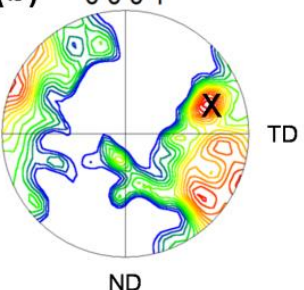

$I_{\text {max }}: 1.4$

(b) $11 \overline{2} 0$

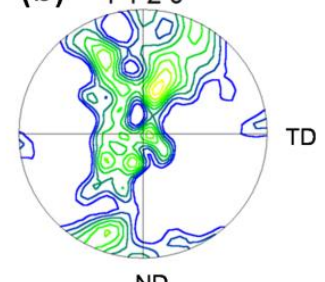

ND (c) 0001

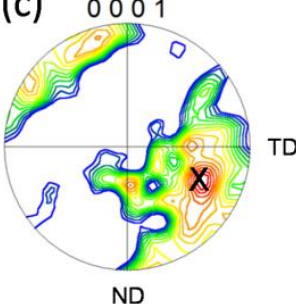

$I_{\text {max }}: 1.4$

(c) $11 \overline{20}$

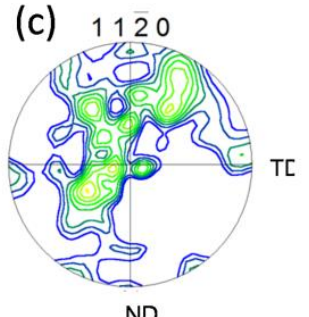

ND

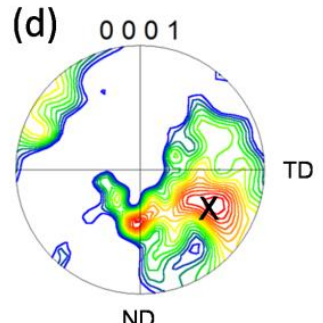

: 1.4

(d) $11 \overline{2} 0$

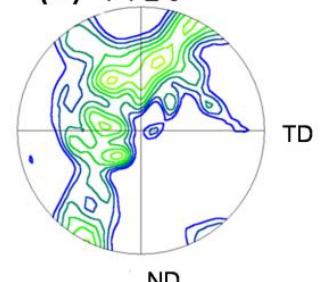

$I_{\text {max }}: 1.2$

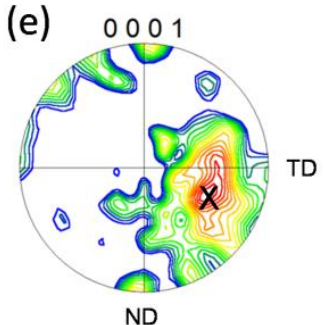

(e) $11 \overline{20}$

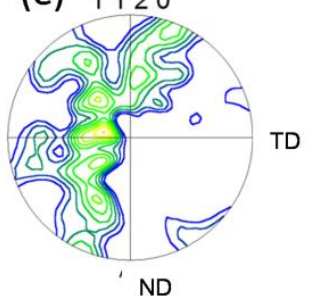

1.2

Fig.11 [0001] and [11-20] pole figures along $1.0 \mathrm{~mm}$ from the top surface in the SZ. (measurement positions are illustrated on the macro graphic above pole figures)

The maximum intensity (Imax) of all the measured positions showed a low value and the change in these are quite small. Mironov et al. (2009) performed the friction stir welding process of ZK60A Mg alloy and reported that the fiber texture was evolved in the SZ. When compared to the texture type with the FSWed of the Mg alloys, which have the same crystal structure (hcp) as the $\alpha-\mathrm{Ti}$, a similar texture type, which is a [0001] fiber texture, was observed in all the measured 
positions; the maximum concentration is found in the [0001] pole figures and the [11-20] is distributed to be rotated around the [0001] maximum concentration axes which act as the rotation center axes. This texture can be regarded as the [0001] fiber texture. The [0001] fiber axis is continuously rotated with the change in the measurement position from the AS to the RS. Park et al. (2003) investigated the texture distribution of the FSWed AZ61 alloy joint and reported that the basal planes were distributed parallel to the probe surface and [0001] $\alpha$ distribution angles were a quite symmetrical with respect to the welding direction. On the other hand, the direction of the strongest concentration of [0001] $\alpha$ in the Ti-6Al-4V alloy joints was totally different from that of the Mg alloy joints. The counter-clockwise rotation angles from the welding direction are about 85, 70, 65, 60 and $55 \mathrm{deg}$ in the a, b, c, d and e regions, respectively.

The rotation angles of [0001] $\alpha$ from the welding direction along the AS to RS in the regions located at a depth of $1.0 \mathrm{~mm}$ from the surface and the SZ center are summarized in Fig. 12. The rotation angle distributions of [0001] $\alpha$ from the welding direction in the FSWed AZ61 joint (Park et al. (2003) ) is denoted by the blue dotted line for comparison. The negative and positive values of the distance indicate the AS and RS, respectively. In all the measurement positions, the [0001] fiber axis rotates in a counter-clockwise direction from the welding direction except for the regions located -2.5 and $2.5 \mathrm{~mm}$ at a depth of $2.5 \mathrm{~mm}$ from the top surface. Since the width of the SZ decreased with the increasing distance from the top surface, the closer distance from the SZ boundary may lead to a constraint in metal flow resulting in the rotation angles of [0001] $\alpha$ in a clockwise direction from the welding direction. Except for the above mentioned peripheral regions, it was found that the tendency in the rotation angles of the [0001] fiber axis continuously changed along the AS to RS. Namely, the [0001] $\alpha$ was perpendicular to the welding direction in the AS, and gradually rotated toward the welding direction when the 
measurement positions were moved to the RS. This result clearly shows the difference in the texture distribution in the SZ between the FSWed Ti alloy and Mg alloy joints. The Ti alloy has a higher work hardening ability than the $\mathrm{Mg}$ alloy, and the difference in the work hardening behavior may lead to a significant change in the plastic behavior between the two materials. Since the deformation texture is evolved by the constraint effect of the plastic deformation in the Ti alloy joint, the lager plastic constraint caused by the higher work hardening ability collapsed the metal flow. As a result, the [0001] $\alpha$ was less rotated through the AS to RS when compared to the $[0001] \alpha$ distribution in the Mg alloy joint. Therefore, it should be noted that not only the crystal structure, but also the plastic behavior have a strong effect on the texture evolution during the FSW.

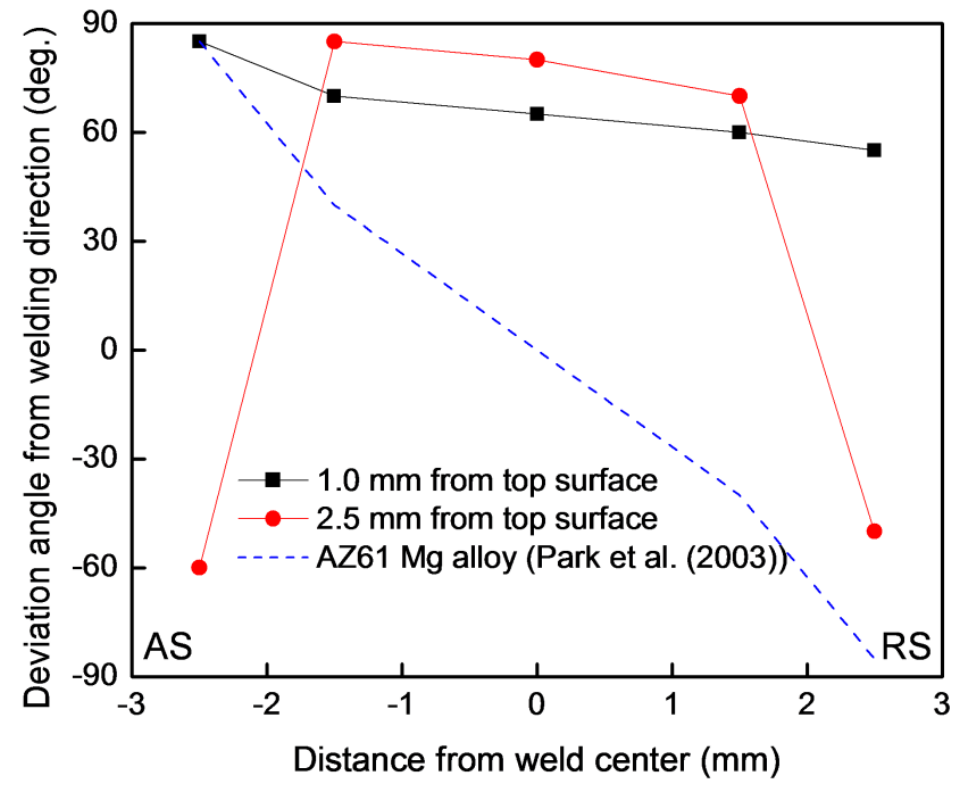

Fig. 12 [0001] $\alpha$ deviation angle from welding direction at regions located at 1.0 and $2.5 \mathrm{~mm}$ from top surface.

\section{Conclusions}


Ti-6Al-4V plates with a thickness of $5 \mathrm{~mm}$ were successfully friction stir welded at a relatively slower tool rotation rate $(50 \mathrm{rpm}, 150 \mathrm{rpm})$ by keeping the temperature at the top surface lower than the $\beta$-transus temperature. The microstructure and the texture distribution in the thickness and the horizontal of the SZ were investigated. The following conclusions were obtained.

(1) The microstructure of the SZ obtained at $50 \mathrm{rpm}$ exhibited the fully equiaxed structure along the plate thickness, while a small amount of the lamellar structure was observed near the top surface in the $150 \mathrm{rpm}$ joint due to the higher peak temperature. When the mean $\alpha$ grain size was compared at the same depth, the $50 \mathrm{rpm}$ joint showed a finer $\alpha$ grain than that of the $150 \mathrm{rpm}$ joint. The mean $\alpha$ grain size decreased with the increasing distance from the top surface. This is due to the peak temperature gradient in the thickness during the FSW process. The hardness distribution of the SZ in thickness well agreed with the $\alpha$ grain size distribution in thickness.

(2) In the area including the lamellar structure, a strong concentration of [0001] $\alpha$ was due to some variant selection during $\beta$ to $\alpha$ transformation.

(3) A bimodal structure was found in the RS of the $\mathrm{SZ}$ obtained at $50 \mathrm{rpm}$. The coarse grain structures were frequently observed in the RS of the SZ center than in the RS located $1.0 \mathrm{~mm}$ below the top surface. This should be due to the gradients in the strain, strain rate and temperature.

(4)The $[0001] \alpha$ concentration angles were a quite symmetrical with respect to the welding direction in the FSWed Mg alloy joints. However, the [0001] $\alpha$ was perpendicular to the welding direction in the AS, and gradually rotated toward the welding direction when the measurement 
positions were moved to the RS in the FSWed Ti alloy joints. This should be due to the difference in the plastic behavior in the Ti alloy caused by the higher work hardening ability.

\section{Acknowledgments}

This study was conducted as a part of the Aerospace Industry Innovation Program-Advanced Materials \& Process Development for Next-Generation Aircraft Structures project under contract with the RIMCOF Research Center of Materials Process Technology Center, established by the Ministry of Economy, Trade and Industry (METI) of Japan. Additionally, this study was supported by the Japan Science and Technology Agency (JST) under Collaborative Research Based on the Industrial Demand, "Heterogeneous Structure Control: Towards Innovative Development of Metallic Structural Materials', The Global COE Program and a Grant-in-Aid for Science Research from the Japan Society for Promotion of Science. 


\section{References}

Aval H., Serajzadeh S., Kokabi A. H., 2011. Theoretical and experimental investigation into friction stir welding of AA 5086. Int. J. Adv. Manuf. Technol., 52, 531-544.

Davies P.S., Wynne B.P., Rainforth W.M., Thomas M.J., Threadgill P.L., 2011. Development of microstructure and crystallographic texture during stationary shoulder friction stir welding of Ti6Al-4V. Metall. Mater. Trans. A, 42A, 2278-2289.

Frederick S. F., Lenning G. A., 1975. Producing Basal Textured Ti-6AI-4V Sheet. Metall. Trans. B, 6B, 601-605.

Fujii H., Sun Y.F., Kato H., Nakata K., 2010. Investigation of welding parameter dependent microstructure and mechanical properties in friction stir welded pure Ti joints. Mater. Sci. Eng. A, 527, 3386-3391.

Kitamura K., Fujii H., Iwata Y., Sun Y.S., Morisada Y., 2013. Flexible control of the microstructure and mechanical properties of friction stir welded Ti-6Al-4V joints. Mater. Des., $46,348-354$.

Mironov S., Motohashi Y., Kaibyshev R., Somekawa H., Mukai T., Tsuzaki K., 2009. Development of fine-grained structure caused by friction stir welding process of a ZK60A magnesium alloy. Mater. Trans., 50, 610-617.

Park S. H. C., Sato Y. S., Kokawa H., 2003. Basal plane texture and flow pattern in friction stir weld of a magnesium alloy, Metall. Mater. Trans. A, 34A, 987-994. 
Pilchak A.L., Williams J.C., 2011. Microstructure and texture evolution during friction stir processing of fully lamellar Ti-6Al-4V. Metall. Mater. Trans. A, 42A, 773-794.

Reynolds A.P., 2008. Flow visualization and simulation in FSW. Scripta Mater., 58, 338-342.

Su J., Wang J., Mishra R.S., Xu R., Baumann J.A., 2013. Microstructure and mechanical properties of a friction stir processed Ti-6Al-4V alloy. Mater. Sci. Eng. A, 573, 67-74.

Thomas W.M., Nicholas D.E., Needham J.C., Murch M.G., Templesmith P., Dawes C.J., 1991. GB Patent Application No. 9125978.8, Dec. 1991.

Yoon S., Ueji R., Fujii H., 2015. Effect of rotation rate on microstructure and texture evolution during friction stir welding of Ti-6Al-4V plates. Mater. Character., $106,352-358$.

Zhang Y., Sato Y.S., Kokawa H., Park S.H.C., Hirano S., 2008. Microstructural characteristics and mechanical properties of Ti-6Al-4V friction stir welds. Mater. Sci. Eng. A, 485, 448-455. 


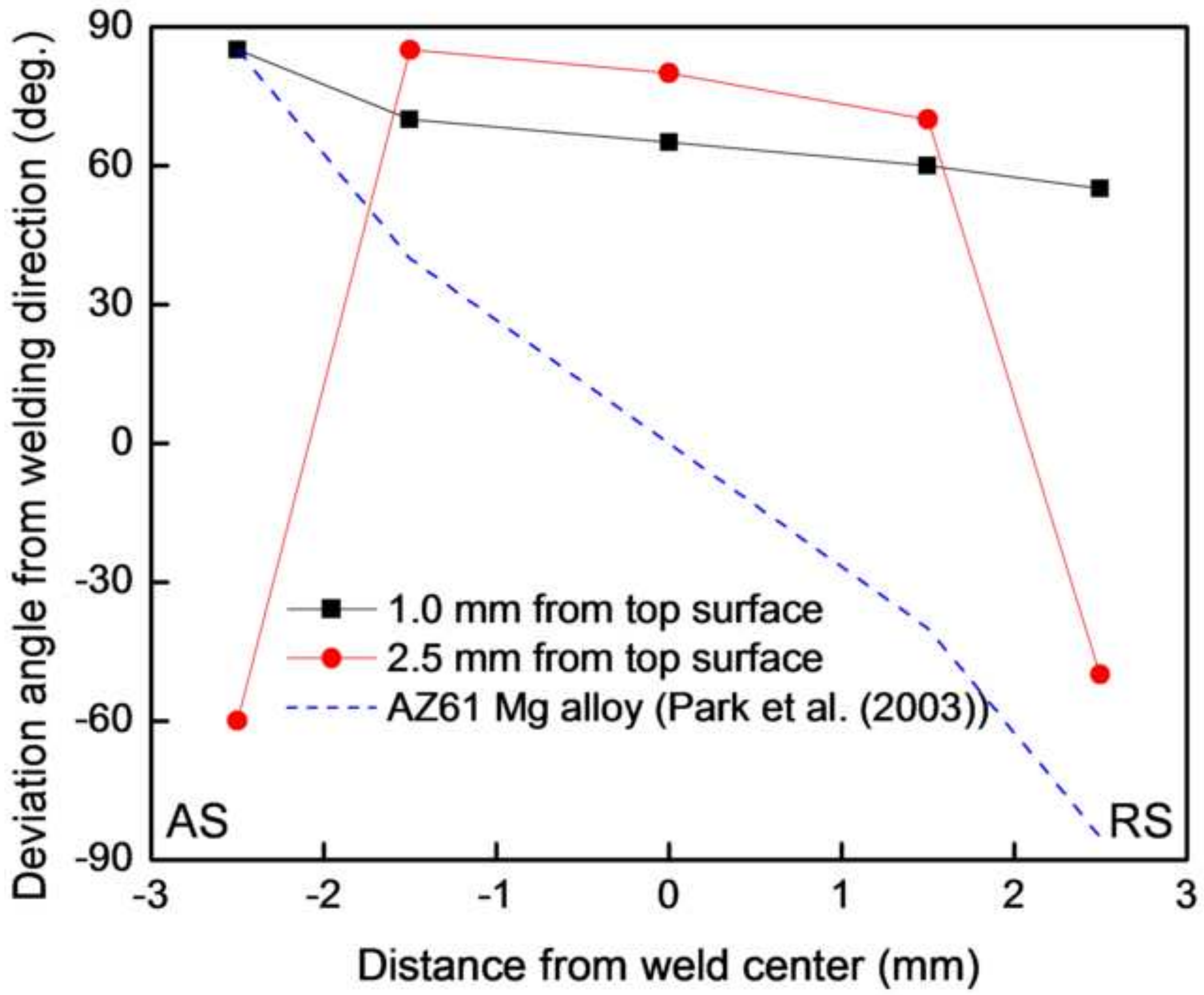

